University of Nebraska - Lincoln

DigitalCommons@University of Nebraska - Lincoln

Sociology Department, Faculty Publications

Sociology, Department of

2011

\title{
Risk Factors for Running Away among a General Population Sample of Males and Females
}

Kimberly A. Tyler

University of Nebraska-Lincoln, kim@ktresearch.net

Kellie J. Hagewen

University of Nebraska-Lincoln, khagewen2@unl.edu

Lisa A. Melander

Kansas State University, Imeland@ksu.edu

Follow this and additional works at: https://digitalcommons.unl.edu/sociologyfacpub

Part of the Psychology Commons, Social Work Commons, and the Sociology Commons

Tyler, Kimberly A.; Hagewen, Kellie J.; and Melander, Lisa A., "Risk Factors for Running Away among a General Population Sample of Males and Females" (2011). Sociology Department, Faculty Publications. 150.

https://digitalcommons.unl.edu/sociologyfacpub/150

This Article is brought to you for free and open access by the Sociology, Department of at DigitalCommons@University of Nebraska - Lincoln. It has been accepted for inclusion in Sociology Department, Faculty Publications by an authorized administrator of DigitalCommons@University of Nebraska - Lincoln. 
Published in Youth \& Society 43(2), pp. 583-608; doi: 10.I I77/0044I I 8XI I 400023 Copyright (c) 201 I Sage Publications. http://yas.sagepub.com Used by permission.

\title{
Risk Factors for Running Away Among a General Population Sample of Males and Females
}

\author{
Kimberly A. Tyler, PhD,' Kellie J. Hagewen, PhD, ' \\ and Lisa A. Melander, PhD ${ }^{2}$ \\ I. University of Nebraska-Lincoln \\ 2. Kansas State University
}

Corresponding author: Kimberly A. Tyler, University of Nebraska-Lincoln, Department of Sociology, 717 Oldfather Hall, Lincoln, NE 68588-0324; email kim@ktresearch.net

\begin{abstract}
The present study examines risk factors for running away and homelessness among a sample of more than 7,000 currently housed youth using the National Longitudinal Study of Adolescent Health (Add Health). Structural equation modeling results revealed that those with greater levels of family instability and those who ran away at Wave 2 were significantly more likely to run away and/ or become homeless 5 years later at Wave 3. Family instability also had a significant indirect effect on running away and/or being homeless at Wave 3 through greater levels of problem behaviors and running away at Wave 2. Running away at Wave I was indirectly associated with running away and/or becoming homeless at Wave 3 through family instability, problem behavior, and Wave 2 running.
\end{abstract}

Keywords: running away, homeless, risk factors 
In the United States alone, it is estimated that 1.6 million youth aged 12 to 17 ran away from home and slept on the street during 2002 (Substance Abuse and Mental Health Services Administration [SAMHSA], 2004). Research conducted with samples of currently homeless and runaway youth finds that these young people experience numerous negative outcomes including involvement in delinquency, risky sexual behavior, and victimization (Tyler, Hoyt, Whitbeck, \& Cauce, 2001). Although there is a considerable body of research on currently homeless individuals, little is known about presently housed adolescents who later run away or become homeless. This is an important group to study because they may also be at risk for experiencing negative outcomes. In addition, the risks associated with this behavior may have cumulative effects that thwart normative adolescent development (Hagan \& McCarthy, 1997; Wheaton, 1999; Whitbeck \& Hoyt, 1999). Understanding more about the risks for running and/or becoming homeless is vital given that running away in adolescence has long-term effects such as early onset of psychological, behavioral, or substance abuse problems that span into adulthood (cf. Simons \& Whitbeck, 1991; Susser, Struening, \& Conover, 1987).

While previous studies have identified troubled family backgrounds as a risk factor for running away (Tyler, Hoyt, \& Whitbeck, 2000; Whitbeck \& Hoyt, 1999), the majority of this research is retrospective and based on samples of currently homeless youth; therefore, the causal ordering of events is unclear. As such, little is known about which risk factors precede running away and/or homelessness. In addition, few studies have been able to examine a multitude of risk factors that account for various facets of the youths' lives including family, environment, and school engagement due to smaller sample sizes. Finally, much of the literature does not explicitly employ any type of theoretical framework to inform analyses or explain empirical findings. As such, the current study examines the effect of family instability, depressive symptoms, problem behaviors, and environmental factors on the likelihood of running away ${ }^{1}$ from home at two subsequent time periods among a sample of youth who are housed at baseline.

\section{Literature Review}

\section{Family Instability}

The literature examining the relationship between family problems and running away is generally consistent. Homeless adolescents typically report higher rates of family conflict and lower rates of parental warmth, 
care, and support compared with their housed counterparts (Dadds, Braddock, Cuers, Elliott, \& Kelly, 1993; Schweitzer, Hier, \& Terry, 1994). Studies also reveal higher levels of child abuse among homeless youth compared with peers who are housed (Plass \& Hotaling, 1995). Not only do those with histories of running away experience more child abuse, but these negative family-of-origin experiences have detrimental impacts on later risk behaviors. For example, studies on homeless and runaway adolescents also find that low levels of warmth and support (Englander, 1984; Fry, 1982), higher levels of rejection (Anooshian, 2005; Whitbeck, Hoyt, \& Ackley, 1997), and experiencing child abuse (Tyler et al., 2001) are associated with running away. In addition, having experienced sexual and/ or physical abuse is associated with more substance use among homeless (Whitbeck \& Hoyt, 1999) and nonhomeless samples (Garnefski \& Arends, 1998; Stock, Bell, Boyer, \& Connell, 1997). Many homeless and runaway youth also have a history of school behavior problems (Toro, Dworsky, \& Fowler, 2007; Whitbeck \& Hoyt, 1999), which is an indicator of social environment, and these have been linked to poor parenting (Hagan \& McCarthy, 1997). It is possible that youth who do not get along with parents, who are resistant to following rules, and who are unwilling to adhere to the demands placed on them by parents may be equally likely to rebel at school where similar controls exist. In sum, family characteristics are linked to problem behaviors and environmental factors, which in turn, are likely to predispose youth to running away from home.

\section{Depressive Symptoms}

Homeless young people in general experience numerous mental health problems including depression (Tyler, Whitbeck, Hoyt, \& Johnson, 2003; Whitbeck, Hoyt, \& Bao, 2000). Although the research is limited, runaways have been found to have higher rates of depression compared with nonrunaways (Ayerst, 1999). Runaway behavior has been linked to depression but the temporal ordering remains unclear due to crosssectional research (de Man, Dolan, Pelletier, \& Reid, 1994). Because longitudinal research on runaways is limited, it is important to determine whether depressive symptoms lead to runaway behavior directly or indirectly through other environmental or social factors.

\section{Problem Behaviors}

Adolescents who engage in problem behaviors are at greater risk for running away (de Man, 2000). One problem behavior that has consistently 
been associated with running away is substance use. For example, a study by SAMHSA (2004) found that the rate of alcohol use, marijuana use, and illicit drug use was higher among adolescents who had run away in the past 12 months compared with those who had not run. Substance use also has been found to be a precipitating factor for becoming homeless (Embry, Vander Stoep, Evens, Ryan, \& Pollak, 2000; Fountain, Howes, Marsden, Taylor, \& Strang, 2003; McNaughton, 2008). Thompson and Pillai (2006) found that adolescents who drank alcohol were more likely to have run away more often compared with those who have never used alcohol.

Although prior empirical work on homeless youth has examined delinquency as an outcome of running away (Whitbeck \& Hoyt, 1999), it is possible that involvement in general delinquency may occur prior to running. Behavioral problems are often initiated within the family context. Inadequately socialized youth often have weakened social controls and may be resistant to conventional norms (Brennan, Huizinga, \& Elliot, 1978). Weakened social controls coupled with familial strain put these youth at an increased risk for engaging in delinquent behavior and adopting antisocial attitudes. As such, delinquent youth may be running away from home to escape these familial problems or spend more time with their delinquent peers (Brennan et al., 1978). In sum, although it has been found that runaway youth engage in delinquent acts while on the street (Baron, 2003; Whitbeck \& Hoyt, 1999), it remains unclear whether delinquency is a precursor to running away from home or is a consequence of it.

\section{Environmental Factors}

Very little research to date has focused on the relationship between environmental risk and running away. Doing poorly in school (English \& English, 1999; Nye, 1980) and school suspension (Tyler \& Bersani, 2008), both of which are indicators of an individual's environment, are associated with running away. Although disadvantaged communities are a risk factor for youth leaving home (Hagan \& McCarthy, 1997), little is known about whether other environmental factors such as physical victimization and neighborhood cohesion also affect young people's decision to run away. In addition, few studies have examined the effect of peers on running away. Existing research tends to focus on youth's participation in problem behaviors (e.g., illicit drug use and risky sexual practices) with other street youth after they have left home (Kipke, Unger, Palmer, Iverson, \& O'Connor, 1998) but do not consider the impact of peers prior to running. Although little research exists on the positive influence of peers among homeless youth, it is possible that those from 
troubled family backgrounds may be less likely to run away if they have supportive and caring friends. Thus peers who provide social support and a sense of belonging (Ennew, 1994; Hagan \& McCarthy, 1997; Unger et al., 1998) may serve a protective role for these youth, decreasing their chances of running away.

\section{Running Away}

As discussed above, numerous risk factors such as child maltreatment, substance use, and delinquency are associated with running away. In addition, research finds that the best predictor of running away is a previous runaway experience (Tyler \& Whitbeck, 2004). For example, Nesmith (2006) found that the risk of running away from foster care was higher for those with a previous running experience. Therefore, it is important to consider previous running experiences when conducting research on the risk factors of runaway behavior.

\section{Background Factors}

Demographic characteristics of the runaway population indicate that poverty (Hagan \& McCarthy, 1997) and being from a broken home (National Center for Juvenile Justice, 1999; Toro et al., 2007) are significant risk factors for running away. Females are also more likely to run away (Government Accounting Office [GAO], 1989) although the findings are mixed with regard to race. For example, in a sample of currently homeless youth, Yoder, Whitbeck, and Hoyt (2001) found that Whites and Blacks were equally likely to run whereas Tyler and Bersani (2008) reported that Blacks and Hispanics were less likely to run among a general adolescent sample.

\section{Theoretical Explanations}

Unlike early theories that viewed runaways as delinquent youth running toward something such as economic or individual freedom (see Wells \& Sandhu, 1986 for a review of the historical perspectives of running away), contemporary literature reveals that runaway and homeless youth are more likely running away from something such as troubled family backgrounds. Although theories have existed since the mid-1970s to explain why youth would run from home (cf. Brennan et al., 1978; Janus, McCormack, Burgess, \& Hartman, 1987; Walker, 1975), the majority of current research on homeless and runaway youth is atheoretical. In the current study, we use the risk amplification model 
(Whitbeck, Hoyt, \& Yoder, 1999), which is a combination of life course and social interaction theories, to explain why youth leave home. This model is useful because it takes into account both factors that influence youth prior to them leaving home (i.e., their family) and those associated with the context of the street environment such as delinquency. As such, it examines both past and present risk factors that are likely to affect youth.

According to this model, adolescents often run from dysfunctional and disorganized homes, such as those characterized by child abuse, neglect, and poor parenting (e.g., low warmth), as a means of escaping a negative home environment. Street experiences are expected to amplify the negative developmental effects originating in the family, and these developmental problems set the stage for participation in high-risk behaviors. Thus, adolescents growing up in families that display aggressive and antisocial behavior may mimic this behavior in other social settings, leading to problem behaviors such as delinquency, substance use, and school-related problems. Cross-sectional research on homeless and runaway youth has generally found support for this risk-amplification process (cf. McMorris, Tyler, Whitbeck, \& Hoyt, 2002; Tyler et al., 2001; Whitbeck \& Hoyt, 1999).

\section{Hypothesized Model}

Based on the above literature review and the risk-amplification framework, we hypothesize a fully recursive model to understand the risk factors that lead youth to run away from home (see Figure 1). As research finds a positive association between child abuse, parental rejection, lower levels of warmth, and running away (Dadds et al., 1993; Englander, 1984; Plass \& Hotaling, 1995; Tyler et al., 2001; Whitbeck et al., 1997), we hypothesize that family instability (e.g., child maltreatment and poor parenting) will have a direct effect on running away. In addition, we expect family instability to have an indirect effect on running away through problem behaviors and environment factors given previous findings (Hagan \& McCarthy, 1997; Toro et al., 2007; Whitbeck \& Hoyt, 1999). Researchers have found that homeless and runaway youth have high rates of depression (Ayerst, 1999; Tyler et al., 2003; Whitbeck et al., 2000); as such, we hypothesize that youth who have more depressive symptoms will be more likely to run away. In addition, it is expected that depressive symptoms will be linked to running away through problem behaviors and environmental factors. Next, because of previous findings, we hypothesize that problem behaviors and environmental risk will both have direct effects on running at Waves 2 


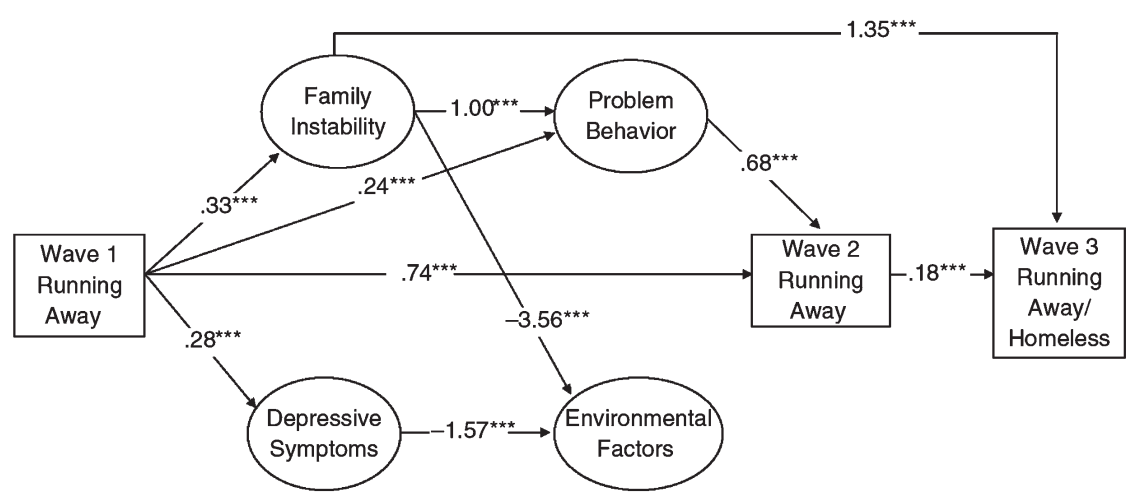

Figure I.SEM model for predictors of running away (only significant paths shown). $* p<$ $.05 ; * * p<.01 ; * * * p<.001$.

and 3 (de Man, 2000; English \& English, 1999; Nye, 1980; Thompson \& Pillai, 2006; Tyler \& Bersani, 2008; Unger et al., 1998). We also expect that problem behaviors and environmental risk will have an indirect effect on running at Wave 3 via running at Wave 2. Given that the best predictor of running away is a previous runaway experience (Nesmith, 2006; Tyler \& Whitbeck, 2004), we hypothesize that those who run away at Wave 2 will be more likely to run at Wave 3. Finally, our model controls for gender, grade, mother's education, household structure, race, and previous episodes of leaving home because the likelihood of running away has been found to vary by these characteristics (GAO, 1989; Toro et al., 2007; Yoder et al., 2001).

\section{Method}

The National Longitudinal Study of Adolescent Health (Add Health) is a nationally representative study that explores the causes of health-related behaviors of adolescents in Grades 7 through 12 and their outcomes in young adulthood (Harris et al., 2008). The Add Health Survey was initiated in 1994 under a grant from the National Institute of Child Health and Human Development with co-funding from 21 other federal agencies and foundations. Add Health is the largest and most comprehensive adolescent longitudinal survey (Harris et al., 2008). The current study makes use of the first three waves of data (Harris, 2008). 
A sample of 80 high schools and 52 middle schools from the Northeastern, Midwestern, Southern, and Western regions of the United States were selected with an unequal probability of selection as a stratified random sample. Interviewers began contacting adolescents from eligible schools and their families between 1994 and 1995 during the first wave of data collection (Harris et al., 2008). Respondents completed in-school questionnaires and then were interviewed at home by trained interviewers. Wave 2 data collection via in-home interviews began in April 1996 and ended in August 1996 and followed the same mode of questioning as in Wave 1. Data collection for Wave 3 began in July 2001 and concluded in April 2002 (Harris et al., 2008). As such, there is approximately a 1-to2-year timeframe between Waves 1 and 2 and almost 5 or 6 years between Waves 2 and 3.

\section{Sample Characteristics}

The current study used a weighted subsample which included 3,914 girls (54.6\%) and 3,248 boys (45.4\%). The respondents were in Grades 7 through 12 at Wave 1 with a median grade of 9. In terms of residential mother's education, $15 \%$ had less than a high school education, 35\% had a high school diploma or GED, and 50\% received training beyond high school. Approximately, $94 \%$ of the current sample reported living with both of their biological parents. The majority of the sample was White $(62.3 \%)$ and $22.1 \%$ were Black and $15.6 \%$ were Hispanic. At Wave 3, approximately $15 \%$ of the sample reported running away or being homeless.

\section{Missing Data}

The present research began with a sample size of 20,186 youth. We retained only those cases with complete data and who participated in all three waves for the analyses. We assessed potential bias due to missing cases with incomplete data by comparing the control variables of the cases with missing data in the analyses with those cases with complete data $(n=7,162)$. We estimated a series of $x^{2}$ and $t$ tests for this purpose. Our results indicated the sample used here is significantly younger $(\bar{X}$ grade $=9.15$ vs. $\bar{X}$ grade $=9.67, p<.001)$, more likely to be female $(54.6 \%$ vs. $50.5 \% ; p<.001)$, to come from a two biological parent household $(94.2 \%$ vs. $76.3 \% ; p<.001)$, to have a mother with a college education or greater $(30.1 \%$ vs. $27.7 \% ; p<.001)$, and significantly less likely to have run away at Wave $1(12.8 \%$ vs. $19.4 \% ; p<.001)$ indicating that our results err on the conservative side. 


\section{Measures}

Demographic controls. The demographic control variables were all measured during Wave 1 . Gender was coded $0=$ male and $1=$ female. The respondent's grade was measured at Wave 1 and ranges from 7 th grade to 12 th grade. For resident mother's education, respondents were asked what level of education their mother had obtained. The response categories included 1 = less than high school, 2 = high school or GED, 3 = beyond high school, and $4=$ college education or more. Household structure was coded $1=$ two biological parent household and $0=$ a household structure other than two biological parents. Race included three dichotomous variables: White non-Hispanic, Black non-Hispanic, and Hispanic of any race. Whites are used as the reference group. Finally, running away at Wave 1 was measured by combining two items: (a) ever spent the night away from home without permission and (b) ever run away from home within the past 12 months. The final dichotomized item was coded $0=$ never ran away from home and 1 = ran away from home.

Family instability. Family instability is a second-order latent construct composed of three latent constructs: child maltreatment, lack of parental warmth, and parental rejection. Prior to testing the structural model, measurement models for each of the latent constructs were estimated. Confirmatory factor analysis (CFA) was used to evaluate whether the model fit the data. Maximum likelihood estimation was used to estimate the model parameters and $\chi^{2}$, the TLI, and the RMSEA to analyze the overall fit of the model. ${ }^{2}$

The child maltreatment variables, measured only at Wave 3, were modified versions of questions administered in previous surveys such as the Revised Conflict Tactics Scale (Straus, Hamby, Boney-McCoy, \& Sugarman, 1996). The child maltreatment latent construct was composed of four observed variables. Physical abuse experience was measured using the following item: "How often had your parents or other adult caregivers slapped, hit, or kicked you?" Experiences of sexual abuse included the following question: "How often had one of your parents or other adult caregivers touched you in a sexual way, forced you to touch him or her in a sexual way, or forced you to have sexual relations?" Neglect was composed of two items that asked them about experiences prior to sixth grade: "How often had your parents or other adult caregivers left you home alone when an adult should have been with you?" and "How often had your parents or other adult caregivers not taken care of your basic needs, such as keeping you clean or providing food or clothing?" The response categories for physical and sexual abuse and neglect included 0 = this has never happened, $1=1$ time, $2=2$ times, $3=3$ to 5 times, $4=6$ to 10 times, and $5=$ more than 10 times. 
Lack of parental warmth, a latent construct measured at Wave 1, included six observed items regarding the respondent's relationship to his or her residential mother and residential father. These items included the following: (a) "Most of the time, your mother/father is warm and loving toward you"; (b) "You are satisfied with the way your mother/father and you communicate with each other"; and (c) "Overall, you are satisfied with your relationship with your mother/father." The mother and father responses to each of the above items were averaged and coded such that a higher score indicated lower levels of parental warmth. Response categories included $0=$ strongly agree, $1=$ agree, $2=$ neither agree nor disagree, 3 $=$ disagree, and $4=$ strongly disagree.

Finally, parental rejection, a latent construct measured at Wave 1, included four observed items from the parent questionnaire. The respondent's caretaker was asked for example how often it would be true for them to make statements such as they get along well with the child and feel they can trust the child. One item (i.e., "You do not understand the child") was reverse coded such that a higher score indicated more parental rejection. Response categories ranged from 0 (always) to 4 (never).

The second-order latent construct family instability was then constructed using the latent constructs of child maltreatment, lack of parental warmth, and parental rejection. The indices of model fit were strong $\left(x^{2}=441.2[d f=41]\right.$, TLI $=0.98$, RMSEA $\left.=0.037\right)$, indicating the model fit the data well. These factor loadings are presented in Table 1.

Depressive symptoms. Depressive symptoms, a second-order latent construct measured at Wave 1, was composed of four latent constructs: depressed mood, positive mood, somatic reactions, and interpersonal relationships. Each observed measure is taken from an 18-item, modified version of the Center for Epidemiologic Studies Scale (Radloff, 1977). Respondents were asked how often each of the statements below were true during the past week and the response categories ranged from 0 (never) to 3 (most or all of the time).

Depressed mood, a latent construct, included the following four observed variables: (a) You felt that you could not shake off the blues, even with help from your family and your friends; (b) You felt depressed; (c) You felt lonely; and (d) You felt sad.

Positive mood, a latent construct, included the following four observed variables: (a) You felt that you were just as good as other people; (b) You felt hopeful about the future; (c) You were happy; and (d) You enjoyed life. These four variables were reverse coded so a higher score indicated more depressive symptoms. 
Table I. Factor Loadings for the CFA (Standardized)

\begin{tabular}{|c|c|c|}
\hline Indicator variables & Factors & Factor loadings \\
\hline \multicolumn{3}{|l|}{ First-order CFA } \\
\hline \multirow[t]{4}{*}{ Environment } & School & 0.607 \\
\hline & Neighborhood & 0.223 \\
\hline & Victimization & 0.477 \\
\hline & Friends & 0.256 \\
\hline \multirow[t]{4}{*}{ Problem behavior } & Binge drinking & 0.487 \\
\hline & Marijuana 0.739 & \\
\hline & Illicit drugs 0.807 & \\
\hline & Delinquency 0.590 & \\
\hline \multicolumn{3}{|l|}{ Second-order CFA } \\
\hline \multirow[t]{14}{*}{ Family instability } & Abuse & 0.336 \\
\hline & Physical abuse & 0.473 \\
\hline & Sexual abuse & 0.466 \\
\hline & Neglect (left alone) & 0.579 \\
\hline & Neglect (basic needs) & 0.453 \\
\hline & Warmth & 0.699 \\
\hline & Warm and loving & 0.775 \\
\hline & Communication & 0.866 \\
\hline & Overall relationship & 0.877 \\
\hline & Reject & 0.495 \\
\hline & Get along & 0.628 \\
\hline & Trust & 0.553 \\
\hline & Understand & 0.445 \\
\hline & Decisions together & 0.658 \\
\hline \multirow[t]{10}{*}{ Depressive symptoms } & Depressed mood & 0.890 \\
\hline & Blues & 0.709 \\
\hline & Depressed & 0.796 \\
\hline & Lonely & 0.685 \\
\hline & Sad & 0.736 \\
\hline & Positive mood & 0.677 \\
\hline & Good as others & 0.482 \\
\hline & Hopeful about future & 0.429 \\
\hline & Happy & 0.740 \\
\hline & Enjoyed life & 0.759 \\
\hline
\end{tabular}


Table I. (continued)

\begin{tabular}{|c|c|c|}
\hline Indicator variables & Factors & Factor loadings \\
\hline & Somatic & 0.901 \\
\hline & Bothered by things & 0.592 \\
\hline & Poor appetite & 0.463 \\
\hline & No focus & 0.585 \\
\hline & Tired & 0.497 \\
\hline & Talked less & 0.383 \\
\hline & Hard to get going & 0.430 \\
\hline & Interpersonal & 0.922 \\
\hline & Failure & 0.601 \\
\hline & Fearful & 0.495 \\
\hline & People unfriendly & 0.393 \\
\hline & People disliked you & 0.514 \\
\hline
\end{tabular}

CFA = confirmatory factor analysis.

Somatic reactions, a latent construct, included the following six observed variables: (a) You were bothered by things that usually don't bother you; (b) You didn't feel like eating, your appetite was poor; (c) You had trouble keeping your mind on what you were doing; (d) You felt that you were too tired to do things; (e) You talked less than usual; and (f) It was hard to get started doing things.

Finally, interpersonal relationships, a latent construct, included the following four observed variables: (a) You thought your life had been a failure; (b) You felt fearful; (c) People were unfriendly to you; and (d) You felt that people disliked you.

The second-order latent construct "depressive symptoms" was then constructed using the latent constructs of depressed mood, positive mood, somatic reactions, and interpersonal relationships. The initial indices of model fit were acceptable $\left(\chi^{2}=2386.1[d f=131]\right.$, TLI $=0.93$, RMSEA $=0.05)$, indicating the model fit the data adequately. The results of the modification indexes (MI) indicated that the model fit would be improved if three covariance paths were added. The addition of these covariates resulted in significantly better values of the fit indexes $\left(\chi^{2}=\right.$ $1060.4[d f=128]$, TLI $=0.97$, RMSEA $=0.030)$. Aside from the empirical evidence from the statistics, the revised measurement model is also a better representation of the data conceptually. Therefore, all the indicators in the original measurement model along with the three covariate paths were retained. These factor loadings are presented in Table 1. 
Problem behaviors. This latent construct was composed of four indicators measured at Wave 2. Binge drinking was measured using a single item that asked respondents on how many days they drank 5 or more drinks in a row over the past 12 months. These items were reverse coded such that a higher score indicated more frequent binge drinking $(0=$ never drank, $1=$ once $a$ month or less, $2=2$ or 3 days a month, $3=1$ or 2 days a week, $4=3$ to 5 days a week, and $5=$ every day or almost every day). Marijuana use was measured using one item that asked respondents whether they had tried or used marijuana since Wave 1 and was coded $0=n o$ and $1=$ yes. Illicit drug usage was measured using three items that asked respondents if they had tried or used cocaine, inhalants, and other illegal drugs (e.g., LSD, PCP, and ecstasy) and coded $0=n o$ and $1=$ yes. A count procedure was performed and then the variable was dichotomized. Finally, delinquency was measured using 13 items such as how often the respondent damaged property, stole a car, shoplifted, or sold drugs within the past 12 months. Response categories were $0=$ never, $1=1$ or 2 times, $2=3$ or 4 times, and $4=5$ or more times. The indices of model fit were acceptable $\left(\chi^{2}=88.6[d f=2]\right.$, TLI $=0.98$, RMSEA $=$ 0.078 ), indicating the model fit the data adequately well. These factor loadings are presented in Table 1.

Environmental factors. This latent construct was composed of four indicators measured at Wave 2. School engagement consisted of five items such as whether the respondent felt close to people at school, felt like a part of their school, and felt safe in school. Response categories ranged from 0 (strongly disagree) to 4 (strongly agree) and a summed scale was created. Neighborhood cohesiveness was measured using four items that asked respondents, for example, whether people in the neighborhood look out for each other and if people usually feel safe in their neighborhood. Response categories included $0=$ false and $1=$ true and were summed. Physical victimization consisted of five items such as how often within the past 12 months the respondent had someone pull a knife or gun on them, shot them, or jumped them. A count procedure was performed and then physical victimization was dichotomized $(0=$ never and $1=$ at least once $)$. Friends support is a single item that asked the respondent how much they feel their friends care about them. Response categories included 0 = not at all, $1=$ very little, $2=$ somewhat, $3=$ quite $a$ bit, and $4=$ very much . The indices of model fit were strong $\left(\chi^{2}=6.25[d f=2]\right.$, TLI $=1.00$, RM$\mathrm{SEA}=0.017$ ), indicating the model fit the data well (see Table 1 for factor loadings).

Running away. Running away was measured at Wave 2 and was composed of two items: how often the respondent ran away from home and if they had ever spent the night away from home without permission. 
The two items were combined into a single variable and coded $0=$ did not run away and $1=$ ran away at least once within the past 12 months.

Running away was measured using five items at Wave 3 and asked respondents about their history of running and being homeless. The first item asked the respondents where they live, and the response categories included $1=$ parent home, $2=$ another person's home, $3=$ own place, $4=$ group quarters, $5=$ homeless, and $6=$ other. This item was recoded such that $0=$ somewhere other than homeless and $1=$ homeless. Three items asked respondents if they had ever (a) run away from home, (b) been homeless a week or more, and (c) ever stayed at a shelter. The response categories for each of these items were $0=n o$ and $1=$ yes. The final item asked whether their parents had ever ordered them out of the home $(0=n o, 1=$ yes, and $2=$ never lived with parents). This item was recoded so $0=$ no or never lived with parents and $1=$ yes. A count procedure was performed and the final variable was dichotomized $(0=$ never ran away/been homeless and $1=$ ran away at least once/ have been homeless).

\section{Results}

The structural equation model (SEM) used the demographics, family instability, depressive symptoms, problem behaviors, environmental factors, and previous running behavior to predict running away at Wave 3. The initial fit statistics of the structural model were satisfactory, $\chi^{2}=$ $5863.861(d f=310)$, TLI $=.814$, RMSEA $=.050$. The results of the MI indicated that the model fit would be improved if several covariance paths were added. The addition of these covariates resulted in significantly better values of the fit indexes, $x^{2}=2596.987(d f=392)$, TLI = 0.94, RMSEA $=0.03$. As the revised structural model is a better representation of the data theoretically, we retained all the indicators in the original structural model along with the covariate paths.

\section{Direct Effects}

Figure 1, which presents the significant paths of our SEM of predictors of running away revealed that one latent construct and one indicator of previous running behavior had significant direct effects on running away at Wave 3. Specifically, those with greater levels of family instability $(\beta$ $=1.35 ; p<.001)$ and those who had previously run away at Wave $2(\beta=$ $0.18 ; p<.001$ ) were significantly more likely to have run away at Wave 3 than their counterparts.

Table 2, which shows the direct, indirect, and total effects for the full model on running away at Wave 3, revealed that two observed 
Table 2. Full-Model Results (Unstandardized)

\begin{tabular}{|c|c|c|c|c|c|c|c|}
\hline \multirow[b]{2}{*}{ Variables } & \multicolumn{2}{|c|}{ Direct effect } & \multicolumn{2}{|c|}{ Total indirect effect } & \multicolumn{3}{|c|}{ Total effect } \\
\hline & Estimate & SE & Estimate & SE & Estima & & SE \\
\hline \multicolumn{8}{|l|}{ Demographic controls } \\
\hline Female & $-0.110^{*}$ & 0.056 & $0.087 *$ & 0.035 & -0.023 & 0.04 & \\
\hline Grade & $-0.14 \mid * * *$ & 0.018 & $0.062 * * *$ & 0.009 & $-0.079 * * *$ & 0.01 & \\
\hline Mothers education & -0.042 & 0.024 & $-0.03 \mid * *$ & 0.012 & $-0.073 * *$ & 0.02 & \\
\hline Household structure & -0.074 & 0.103 & $-0.143 * * *$ & 0.043 & $-0.216 *$ & 0.09 & \\
\hline Black & -0.057 & 0.070 & 0.025 & 0.038 & -0.032 & 0.06 & \\
\hline Hispanic & 0.079 & 0.078 & 0.007 & 0.045 & 0.086 & 0.07 & \\
\hline \multicolumn{8}{|l|}{ Latent constructs } \\
\hline Family instability & $1.350 * * *$ & 0.233 & $0.223 *$ & 0.112 & $1.573^{* * *}$ & 0.19 & \\
\hline Depressive symptoms & -0.070 & 0.083 & 0.069 & 0.047 & -0.001 & 0.07 & \\
\hline Problem behavior & -0.058 & 0.070 & & & & & \\
\hline Environmental factors & -0.029 & 0.029 & & & & & \\
\hline \multicolumn{8}{|l|}{ Previous running } \\
\hline Wave I & 0.061 & 0.079 & $0.652 * * *$ & 0.054 & $0.712 * * *$ & 0.06 & \\
\hline Wave 2 & $0.175 * * *$ & 0.033 & & & & & \\
\hline
\end{tabular}

$* p<.05 ; * * p<.01 ; * * * p<.001$

demographic variables were also significant. Females $(\beta=-0.110 ; p<$ $.05)$ and those in a higher grade at baseline $(\beta=-0.141 ; p<.001)$ were significantly less likely to have run away at Wave 3 than were their counterparts.

\section{Indirect Effects}

In terms of total indirect effects, four observed demographic variables, one latent construct, and one indicator of previous running behavior had significant indirect effects on running away at Wave 3 (see Table 2). In addition to the positive direct effect, family instability also had a significant indirect effect on running away at Wave 3 through two variables. Specifically, youth with greater family instability had significantly higher levels of problem behaviors, which in turn was positively associated with running away at Wave 2 and those who ran away at Wave 2 were more 
likely to run again at Wave 3 . The finding that family instability continues to affect a youth's chances of running away at a later time point is especially noteworthy given that these two measures are separated by a period of 5 years.

Gender was indirectly associated with running away at Wave 3 through three different avenues. First, girls indicated significantly higher levels of family instability, which in turn was positively associated with running away at Wave 3 . Second, girls with higher levels of family instability had greater levels of problem behavior, which in turn was significantly associated with running away at Wave 2 and those who ran at Wave 2 were more likely to repeat this behavior at Wave 3. Finally, gender was indirectly associated with running at Wave 3 through problem behavior and Wave 2 running away.

There were three significant indirect paths between baseline grade level and running away at Wave 3. First, baseline grade level was positively associated with family instability, which in turn led to running away at Wave 3. Second, a higher grade level at baseline was positively related to running at Wave 2, and those who ran at Wave 2 were more likely to run again at Wave 3. Finally, a higher grade at baseline was indirectly associated with running at Wave 3 via more family instability, greater level of problem behaviors, and Wave 2 running.

Although neither demonstrated a significant direct effect with the outcome variable, both mother's level of education and household structure had significant, negative indirect effects on running away at Wave 3. Youth who have mothers with lower education and those who do not have both biological parents present in the household had higher levels of family instability, which in turn was positively associated with running away at Wave 3. In addition, mother's education and family structure were both associated with running at Wave 3 through family instability, problem behaviors, and running away at Wave 2 .

Finally, although running at Wave 1 did not have a significant direct effect on running at Wave 3 , it was indirectly associated with running at Wave 3 through four different avenues, indicating that adolescents who ran from home at Wave 1 were more likely to run again 5 years later as young adults. Three indirect effects operated solely through running away at Wave 2, family instability, and problem behavior and the fourth route was through all three of these variables.

\section{Discussion}

The purpose of this study was to examine the effect of family instability, depressive symptoms, problem behaviors, and environmental factors on 
the likelihood of running away from home at two subsequent time periods among a sample of youth housed at baseline. Our results indicate that higher levels of family instability have both direct and indirect effects on running away at Wave 3. This is consistent with both our hypotheses and the current literature.

Comparison studies find that homeless adolescents report higher rates of family conflict and lower rates of parental warmth, care, and support compared with their housed counterparts (Dadds et al., 1993; Schweitzer et al., 1994). In addition, studies on homeless and runaway adolescents find that child maltreatment leads to running away (Tyler et al., 2001; Whitbeck et al., 1997). We also find that family instability indirectly affects running away via problem behaviors. This finding is especially noteworthy given that family instability and problem behaviors are separated from running away by at least 5 years. It is very likely that youth who have unsatisfactory relationships with their parents, who lack communication with parents, or feel that their parents do not trust them are more inclined to leave home. In addition, young people who experience conflict and abuse in their family of origin may be more likely to gravitate toward high-risk behaviors such as substance use and delinquent activities, which is consistent with previous literature on nonhomeless samples (Garnefski \& Arends, 1998; Stock et al., 1997). Furthermore, the potential trauma associated with early negative family experiences (e.g., abuse and/or neglect) may have cumulative effects (Hagan \& McCarthy, 1997; Wheaton, 1999). Finally, additional long-term consequences for these youth may include lowered self-esteem and difficulties forming normative relationships. Thus, our findings indicate that family instability continues to plague youth several years later and that many of these individuals are at subsequent risk for running away.

Although family instability and depressive symptoms both had direct effects on environmental factors, the latter was not significantly associated with running at Wave 3 which is contrary to expectations. Very little research has examined the effect of environmental factors on running away; however, studies on the individual risks (i.e., school engagement, neighborhood cohesiveness, and physical victimization) have found some support for this link (English \& English, 1999; Nye, 1980). Thus environmental factors are important outcomes of family instability, but they are not powerful enough, at least among our sample, to account for why youth run from home. One possible reason for the lack of a significant finding may be that our indicators captured only severe physical victimization and many youth may have not had such experiences within their neighborhood. In addition, many youth may be unfamiliar with how cohesive their neighborhood is, which may be why we had little variability within this construct. 
We also find that problem behavior had a significant indirect effect on our outcome variable through running away at Wave 2 . This indicates that youth who are involved in delinquent activities are more likely to run from home and those who have run are at significantly greater risk for doing so in the future. In fact, running away at Wave 2 significantly predicts running away 5 years later. This is such a noteworthy finding because it shows how detrimental running away from home can be for young people. In other words, although running away from home may be a one-time event for some youth, others who run are going to find themselves leaving home again or subsequently becoming homeless as a young adult. Although running at Wave 1 did not directly predict running at Wave 3, it was indirectly associated through family instability, problem behavior, and running at Wave 2. It is possible that the reason youth who run are at risk for repeating this behavior is because they have already begun to participate in deviant behaviors on the street and are potentially at risk for forming ties with others who share their interests. In addition, using alcohol or drugs may result in some youth dropping out of school and/or having difficulties holding down a job, which may lead to homelessness. Furthermore, if they are participating in problem behaviors while still living at home, their families may order them to leave. Our finding that running away predicts future episodes of this behavior is consistent with previous research (Nesmith, 2006; Tyler \& Whitbeck, 2004) and our hypothesis.

In terms of background characteristics, several variables had both direct and indirect effects on running at Wave 3. Girls and those in a higher grade were significantly less likely to run at Wave 3 . The finding for gender is contrary to expectations and some research on running behaviors (Tyler \& Bersani, 2008). One likely explanation for why girls are less likely to run at Wave 3 is that our outcome variable also included indicators of being homeless for which males are at greater risk (GAO, 1989). We also find that Black and Hispanic youth did not significantly differ in their runaway behavior at Wave 3. It is possible that exposure to family instability leads to high-risk outcomes regardless of race or ethnic background.

In addition to explaining risk factors associated with running away, we also wanted to examine the predictive utility of the risk-amplification model to see whether previous findings based on samples of currently homeless and runaway youth could be replicated among a general population sample of youth housed at baseline. Our results are somewhat consistent with this model. Adolescents who have higher rates of family instability including experiences of maltreatment, lack of parental warmth, and more parental rejection are at greater risk for running away. 
Although studies using the risk amplification model have been typically based on cross-sectional analyses, the current findings reveal that negative family experiences continue to affect youth such that family instability indirectly predicts running away 5 years later through problem behavior and running at Wave 2.

Our findings on problem behavior are also consistent with a risk amplification interpretation. Although retrospective studies find that homeless and runaway youth engage in delinquent acts while on the street (Baron, 2003; Whitbeck \& Hoyt, 1999), it remains unclear whether delinquency in itself is a precursor to running away from home or is a result of it given the cross-sectional nature of these studies. In the current study, we find that problem behavior indirectly affects running at Wave 3 through an earlier episode of running. Our findings also indicate that running at Wave 1 leads to problem behaviors at Wave 2 . As such, our findings are supportive of previous research on currently homeless samples (Whitbeck \& Hoyt, 1999) such that after youth run from home, they become involved in delinquent behavior. Our findings also bring to light the fact that the process is more complicated than running simply leading to problem behavior. That is, problem behavior is associated with Wave 2 running and it continues to affect running away 5 years later. Thus, consistent with Whitbeck and colleagues' (1997) interpretation, it is possible that many youth may experience ineffective parenting, leading to a weakening of social controls and resulting in youth's participation in numerous deviant behaviors. In sum, many youth engaging in problem behavior may be more apt to run away from home to escape family problems. Alternatively, some youth may be forced to leave home by their parents because of their participation in problem behaviors.

Some limitations should be noted with this study. As with any secondary longitudinal data set, the advantages gained by the large sample size and the rich data are matched by the loss of important research-specific questions. For example, this data set did not include any indicators of their friend's delinquent behavior that are typically found in the literature on homeless youth (e.g., selling drugs, threatening someone with a weapon). As these items have been found to be of significant importance (Hagan \& McCarthy, 1997), this may have accounted for the lack of significant findings for our environmental construct. Second, the data limited our ability to measure the duration of time adolescents spent away from home. Third, the measures of child maltreatment were retrospective; thus the current situation of some youth may have influenced their responses to these questions. Fourth, our control for attrition bias on running away was significant indicating that runaways were more likely to be missing from the sample. 
Notwithstanding these concerns, our data also have several strengths, which allowed us to address many of the shortcomings in the current literature. We were able to use a prospective, longitudinal data set of more than 7,000 adolescents and youth in the general population, which allowed us to examine antecedents of running. In addition to including measures of parenting and child maltreatment, that are generally related to youth running away from home among cross-sectional studies, we also included indicators of problem behaviors and environmental risk, which typically have not been examined as precursors of running away. We also employed a theoretical framework that takes into account family, problem behaviors, and school and environmental issues that explain why youth may run away from home. Finally, the data permitted us to examine how certain risk factors affect the likelihood of running away 5 years later. This is extremely important because it allowed us to show how early family histories and participation in problem behaviors continue to have an impact on youth as they reach young adult status. In other words, unstable family histories continue to negatively affect youth as they develop and can have detrimental effects for youths' emotional and physical well-being.

Our findings shed important light on precursors to running away among boys and girls in the general population. This information is important because it may allow practitioners and other professionals to target high-risk groups and to intervene before adolescents initially run from home. Furthermore, our findings highlight the fact that youth who initially run away are at risk for repeating this behavior. As such, it is very important to target this group of initial runners before they form ties with street youth. If we wait too long, these young people may become embedded in street culture making it more difficult for them to return home (Auerswald \& Eyre, 2002). Another noteworthy finding is the direct link between family instability and running away 5 years later. This is particularly relevant given the current economic challenges in the United States. Adolescents in families that are experiencing some of the worst economic constraints, such as female headed households, may be at greater risk for running away and thus are a group that should be targeted for intervention. Although both boys and girls in high-risk households should be targeted, we find that females have higher family instability, indicating that they are at even greater risk for running away. As such, young women who come from homes marked by more instability may need to receive additional services such as intensive counseling to prevent this high-risk behavior. Thus initial efforts to intervene during early adolescence are needed as this may be an opportune time to protect these youth from the detrimental effects of running away. Overall, identifying problems associated with running away is important because 
problems left unchecked may result in repeated running, which leads to a greater likelihood of spending time on the street and thus increasing the risk for substance misuse, victimization, delinquency, and high-risk sexual behaviors (McMorris et al., 2002; Tyler et al., 2000; Tyler \& Johnson, 2004).

Acknowledgments - Special acknowledgment is due Ronald R. Rindfuss and Barbara Entwisle for assistance in the original design. This research uses data from Add Health, a program project designed by J. Richard Udry, Peter S. Bearman, and Kathleen Mullan Harris, and funded by a grant P01HD31921 from the Eunice Kennedy Shriver National Institute of Child Health and Human Development, with cooperative funding from 17 other agencies. Persons interested in obtaining data files from Add Health should contact Add Health, Carolina Population Center, 123 W. Franklin Street, Chapel Hill, NC 27516-2524 (addhealth@unc.edu). No direct support was received from grant P01-HD31921 for this analysis.

\section{Notes}

1. Much of the research conducted on this population includes samples of both runaway and homeless youth and the two terms are often used interchangeably. Although our dependent variable at Wave 3 includes measures of both running away and homelessness, we use the term running away when referring to this measure for simplicity.

2. Recent research has proposed a two-index criterion for assessing the adequacy of model fit (Hu \& Bentler, 1999). This study reports two noncentrality-based indices: The Tucker-Lewis Index (TLI) and the root mean square error of approximation (RMSEA). The TLI is an incremental fix index and measures the proportionate improvement in fit by comparing a target model with a more restricted, nested baseline model (Bentler, 1988). Hu and Bentler (1999) support the use of TLI, as it is relatively insensitive to sample size and is sensitive to model misspecifications. TLI values greater than or equal to 0.9 indicates acceptable model fit (Hu \& Bentler, 1999). The RMSEA estimates the lack of fit in a model compared with a saturated model (Browne \& Cudeck, 1993; Steiger, 1990). A value of .05 or lower indicates a good fit and values up to .08 indicate an acceptable fit (Browne \& Cudeck, 1993; Hu \& Bentler, 1999). 


\section{References}

Anooshian, L. J. (2005). Violence and aggression in the lives of homeless children: A review. Aggression \& Violent Behavior, 10, 129-152.

Auerswald, C., \& Eyre, S. L. (2002). Youth homelessness in San Francisco: A life cycle approach. Social Science E Medicine, 54, 1497-1512.

Ayerst, S. L. (1999). Depression and stress in street youth. Adolescence, 34, 567-575.

Baron, S. W. (2003). Self-control, social consequences, and criminal behavior: Street youth and the general theory of crime. Journal of Research in Crime and Delinquency, 40, 403-425.

Bentler, P. M. (1988). Comparative fit indexes in structural models. Psychological Bulletin, 88, 588-606.

Brennan, T., Huizinga, D., \& Elliot, D. S. (1978). The social psychology of runaways. Lexington, MA: Lexington Books.

Browne, M. W., \& Cudeck, R. (1993). Alternative ways of assessing model fit. In K. A. Bollen, \& J. S. Long (eds.), Testing structural equation models (pp. 132-162). Newbury, CA: SAGE.

Dadds, M., Braddock, D., Cuers, S., Elliott, A., \& Kelly, A. (1993). Personal and family distress in homeless adolescents. Community Mental Health Journal, 29, 413-422.

de Man, A. F. (2000). Predictors of adolescent running away behavior. Social Behavior \& Responsibility, 28, 261-268.

de Man, A., Dolan, D., Pelletier, R., \& Reid, C. (1994). Adolescent running away behavior: Active or passive avoidance? Journal of Genetic Psychology, 155, 59-64.

Embry, L. E., Vander Stoep, A., Evens, C., Ryan, K. D., \& Pollak, A. (2000). Risk factors for homelessness in adolescents released from psychiatric residential treatment. Journal of the American Academy of Child $\mathcal{E}$ Adolescent Psychiatry, 39, 1293-1299.

Englander, S. W. (1984). Some self-reported correlates of runaway behavior in adolescent females. Journal of Consulting and Clinical Psychology, 52, 484-485.

English, N. D., \& English, L. M. (1999). A proactive approach to youth who run. Child Abuse \& Neglect, 23, 693-698.

Ennew, J. (1994). Parentless friends: A cross-cultural examination of networks among street children and street youth. In F. Nestmann \& K. Hurrelmann (eds.), Social networks and social support in childhood and adolescence (pp. 409-426). Berlin, Germany: de Gruyter.

Fountain, J., Howes, S., Marsden, J., Taylor, C., \& Strang, J. (2003). Drug and 
alcohol use and the link with homelessness: Results from a survey of homeless people in London. Addiction Research \& Theory, 11, 245-256.

Fry, P. S. (1982). Paternal correlates of adolescents' running away behaviors: Implications for adolescent development and considerations for intervention and treatment for adolescent runaways. Journal of Applied Developmental Psychology, 3, 347-360.

Garnefski, N., \& Arends, E. (1998). Sexual abuse and adolescent maladjustment: Differences between male and female victims. Journal of Adolescence, 21, 99-107.

Government Accounting Office. (1989). Homeless and runaway youth receiving services at federally funded shelters (Report HRD-90-45). Washington, DC: Author.

Hagan, J., \& McCarthy, B. (1997). Mean streets: Youth crime and homelessness. New York, NY: Cambridge University Press.

Harris, K. M. (2008). The National Longitudinal Study of Adolescent Health (Add Health), Waves I \& II, 1994-1996; Wave III, 2001-2002 [machine-readable data file and documentation]. Chapel Hill: Carolina Population Center, University of North Carolina at Chapel Hill.

Harris, K. M., Halpern, C. T., Entzel, P., Tabor, J., Bearman, P. S., \& Udry, J. R. (2008). The National Longitudinal Study of Adolescent Health: Research. Online at http://www.cpc.unc.edu/projects/addhealth/design

Hu, L., \& Bentler, P. M. (1999). Cutoff criteria for fit indexes in covariance structure analysis: Conventional criteria versus new alternatives. Structural Equation Modeling, 6, 1-55.

Janus, M., McCormack, A., Burgess, A. W., \& Hartman, C. (1987). Adolescent runaways: Causes and consequences. Lexington, MA: Lexington Books.

Kipke, M. D., Unger, J. B., Palmer, R. F., Iverson, E., \& O'Connor, S. (1998). Association between self-identified peer-group affiliation and HIV risk behaviors among street youth. In J. B. Greenberg \& M. S. Neumann (eds.), What we have learned from the AIDS evaluation of street outreach projects (pp. 61-82). Atlanta, GA: Centers for Disease Control.

McMorris, B. J., Tyler, K. A., Whitbeck, L. B., \& Hoyt, D. R. (2002). Familial and "on the street" risk factors associated with alcohol use among homeless and runaway adolescents. Journal of Studies on Alcohol, 62, 34-43.

McNaughton, C. C. (2008). Transitions through homelessness, substance use, and the effect of material marginalization and psychological trauma. Drugs: Education, Prevention and Policy, 15, 177-188.

National Center for Juvenile Justice. (1999). Juvenile offenders and victims: 1999 national report. U.S. Department of Justice. Online at http://ncjrs.org/ html/ojjdp/nationalreport99/toc.html 
Nesmith, A. (2006). Predictors of running away from family foster care. Child Welfare, 85, 585-609.

Nye, F. I. (1980). A theoretical perspective on running away. Journal of Family Issues, 1, 274-299.

Plass, P. S., \& Hotaling, G. T. (1995). The intergenerational transmission of running away: Childhood experiences of the parents of runaways. Journal of Youth and Adolescence, 24, 335-348.

Radloff, L. S. (1977). The CES-D Scale: A self-report depression scale for research in the general population. Applied Psychological Measurement, 1, 385-401.

Schweitzer, R., Hier, S., \& Terry, D. (1994). Parental bonding, family systems, and environmental predictors of adolescent homelessness. Journal of Emotional and Behavioral Disorders, 2, 39-45.

Simons, R., \& Whitbeck, L. (1991). Running away during adolescence as a precursor to adult homelessness. Social Service Review, 65, 224-247.

Steiger, J. H. (1990). Structural model evaluation and modification: An interval estimation approach. Multivariate Behavioral Research, 225, 173-180.

Stock, J. L., Bell, M. A., Boyer, D. K., \& Connell, F. A. (1997). Adolescent pregnancy and sexual risk-taking among sexually abused girls. Family Planning Perspectives, 29, 200-227.

Straus, M. A., Hamby, S. L., Boney-McCoy, S., \& Sugarman, D. B. (1996). The Revised Conflict Tactics Scales (CTS2): Developmental and preliminary psychometric data. Journal of Family Issues, 17, 283-316.

Substance Abuse and Mental Health Services Administration. (2004). Substance use among youths who had run away from home (The NSDUH Report). Rockville, MD: Office of Applied Studies.

Susser, E., Struening, E., \& Conover, S. (1987). Childhood experiences of homeless men. American Journal of Psychiatry, 144, 1599-1601.

Thompson, S. J., \& Pillai, V. K. (2006). Determinants of runaway episodes among adolescents using crisis shelter services. International Journal of Social Welfare, 15, 142-149.

Toro, P. A., Dworsky, A., \& Fowler, P. J. (2007). Homeless youth in the United States: Recent research findings and intervention approaches. Unpublished manuscript.

Tyler, K. A., \& Bersani, B. E. (2008). A longitudinal study of early adolescent precursors to running away. Journal of Early Adolescence, 28, 230-251.

Tyler, K., Hoyt, D., \& Whitbeck, L. (2000). The effects of early sexual abuse on later sexual victimization among female homeless and runaway adolescents. Journal of Interpersonal Violence, 15, 235-250. 
Tyler, K. A., Hoyt, D. R., Whitbeck, L. B., \& Cauce, A. M. (2001). The impact of childhood sexual abuse on later sexual victimization among runaway youth. Journal of Research on Adolescence, 11, 151-176.

Tyler, K. A., \& Johnson, K. A. (2004). Victims and offenders: Accounts of paybacks, invulnerability, and financial gain among homeless youth. Deviant Behavior, 25, 427-449.

Tyler, K. A., \& Whitbeck, L. B. (2004). Lost childhoods: Risk and resiliency among runaway and homeless adolescents. In P. Allen-Meares \& M. W. Fraser (eds.), Intervention with children and adolescents: An interdisciplinary perspective (pp. 378-397). Boston, MA: Pearson Education.

Tyler, K. A., Whitbeck, L. B., Hoyt, D. H., \& Johnson, K. D. (2003). Self-mutilation and homeless youth: The role of family abuse, street experiences, and mental disorders. Journal of Research on Adolescence, 13, 457-474.

Unger, J. B., Kipke, M. D., Simon, T. R., Johnson, C. J., Montgomery, S. B., \& Iverson, E. (1998). Stress, coping, and social support among homeless youth. Journal of Adolescent Research, 13, 134-157.

Walker, D. K. (1975). Runaway youth: An annotated bibliography and literature overview. Washington, DC: U.S. Department of Health, Education, and Welfare, Office of the Assistant Secretary of Planning and Evaluation, Office of Social Services and Human Development.

Wells, M., \& Sandhu, H. S. (1986). The juvenile runaway: A historical perspective. Free Inquiry in Creative Sociology, 14, 143-147.

Wheaton, B. (1999). The nature of stressors. In A. V. Horowitz \& T. L. Scheid (eds.), A handbook for the study of mental health: Vol. 1, Social contexts, theories, and systems (pp. 176-197). New York, NY: Cambridge University Press.

Whitbeck, L. B., \& Hoyt, D. R. (1999). Nowhere to grow: Homeless and runaway adolescents and their families. New York, NY: Aldine de Gruyter.

Whitbeck, L. B., Hoyt, D. R., \& Ackley, K. A. (1997). Abusive family backgrounds and later victimization among runaway and homeless adolescents. Journal of Research on Adolescence, 7, 375-392.

Whitbeck, L., Hoyt, D., \& Bao, W. (2000). Depressive symptoms and co-occurring depressive symptoms, substance abuse, and conduct problems among runaway and homeless adolescents. Child Development, 71, 721-732.

Whitbeck, L. B., Hoyt, D. R., \& Yoder, K. A. (1999). A risk-amplification model of victimization and depressive symptoms among runaway and homeless adolescents. American Journal of Community Psychology, 27, 273-296.

Yoder, K. A., Whitbeck, L. B., \& Hoyt, D. R. (2001). Event history analysis of antecedents to running away from home and being on the street. American Behavioral Scientist, 45, 51-65. 


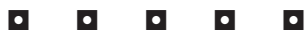

\begin{abstract}
About the Authors
Kimberly A. Tyler, PhD, is a professor in the Department of Sociology at the University of Nebraska-Lincoln. Her research interests include homelessness, child abuse and neglect, victimization, and high-risk behaviors among adolescents and youth.
\end{abstract}

Kellie J. Hagewen, PhD, is an assistant professor in the Department of Sociology at the University of Nebraska-Lincoln. Her research interests include medical sociology, demography, and race/ethnic/minority inequality.

Lisa A. Melander, PhD, is an assistant professor in the Department of Sociology, Anthropology, and Social Work at Kansas State University. Her primary research interests include intimate partner violence, child abuse and neglect, and adolescent high-risk behaviors. 